\title{
O amor e as suas relações com a alteridade, o desejo e a criação
}

\section{Love and its relations with alterity, desire and creation}

\author{
El amor y sus relaciones con la alteridad, el deseo y la \\ creación
}

\author{
Rebeca Gomes* \\ Universidade Federal do Ceará - UFC, Fortaleza, Ceará, Brasil \\ José Célio Freire** \\ Universidade Federal do Ceará - UFC, Fortaleza, Ceará, Brasil
}

\begin{abstract}
RESUMO
Seduzidos pelo fascínio que o amor exerce nos mais diversos âmbitos da experiência humana, e convencidos da natureza polissêmica e sempre renovada dos nós amorosos, sentimo-nos instigados a investigar o lugar reservado à alteridade nas relações amorosas na contemporaneidade. Para tanto, estudamos a temática do amor, abordando-a sob diferentes enfoques teóricos. Dentre eles, destacamos as considerações de Zygmunt Bauman, Emmanuel Lévinas, Anthony Giddens e Gilles Lipovetsky, ao mesmo tempo em que, como substrato teórico, atrelamo-nos à noção psicanalítica do amor como suplência à falta constitutiva do sujeito. Por fim, persuadidos das múltiplas formas de arranjo entre o amor e a alteridade, seja pautada pela ética de uma alteridade radical, pela demanda narcísica de um modelo hedonista de sociedade ou pela frouxidão dos laços de um amor líquido, apontamos que, para além dessas questões, o amor encerra uma dimensão estética, cuja relação estabelece-se com o desejo, a beleza e a criação.
\end{abstract}

Palavras chave: amor, alteridade, desejo, criação.

\begin{abstract}
Seduced by the allure that love carries on in the most diverse areas of human experience and convinced of the polysemic nature and always renewed love knots, we are encouraged to investigate the place reserved for alterity in romantic relationships in contemporary times. We studied the theme of love, addressing her under different theoretical approaches. Among them, we highlight the considerations of Zygmunt Bauman, Emmanuel Lévinas, Anthony Giddens and Gilles Lipovetsky, while at the same time, we support in the psychoanalytic notion of love as assistance to human incompleteness. Finally, persuaded of the multiple forms of arrangement between love and alterity, is marked by a radical alterity ethics, by narcissistic demand of a hedonistic model of society or by the fragile connections of love liquid, beyond those issues, we observe that love evokes an esthetic dimension, whose relationship is established with the desire, the beauty and creation.
\end{abstract}


Keywords: love, alterity, desire, creation.

\begin{abstract}
RESUMEN
Seducidos por el encanto que el amor ejerce en las más diversas áreas de la experiencia humana y convencidos del carácter polisémico y siempre renovado de los nudos de amor, nos animamos a investigar el lugar reservado para la alteridad en las relaciones amorosas en la contemporaneidad. Con este fin, hemos estudiado el tema del amor, abordándolo desde diferentes enfoques teóricos. Entre ellos, podemos destacar las consideraciones de Zygmunt Bauman, Emmanuel Lévinas, Anthony Giddens y Gilles Lipovetsky, mientras que, al mismo tiempo, nos apoyamos en la noción psicoanalítica del amor como suplencia a la falta constitutiva del sujeto. Finalmente, convencidos de las múltiples formas de arreglo entre el amor y la alteridad, sea marcada por una ética de la alteridad radical, por una demanda narcisista de un modelo hedonista de sociedad o por la flojedad de los vínculos del amor líquido, señalamos que, además de estas cuestiones, el amor evoca una dimensión estética, cuya relación se establece con el deseo, la belleza y la creación.
\end{abstract}

Palabras clave: amor, alteridad, deseo, creación.

O presente trabalho, em um primeiro plano, é fruto de um interesse oriundo do poder de fascínio que o amor exerce nos mais diversos âmbitos da experiência humana. Ademais, dada a polissemia, sempre renovada, dos nós amorosos, sentimo-nos instigados a investigar o lugar reservado à alteridade nas relações amorosas na contemporaneidade. Para tanto, estudamos a temática do amor, abordando-a sob diferentes enfoques teóricos.

No que diz respeito a eles, vale dizer que as perspectivas aqui apresentadas justificam-se pelo fato de que, não obstante o seu modo particular de abordagem das relações amorosas, todas se debruçam sobre a tônica do amor e empreendem uma leitura significativamente crítica acerca do lugar do outro nos arranjos amorosos que pululam na contemporaneidade. Assim, considerando que os pressupostos escolhidos contribuem, substancialmente, para a investigação que pretendemos, nós os adotaremos como fio condutor de nosso trabalho e, a partir deles, esperamos poder chegar a novas propostas e a novas conclusões. Dessa forma, a partir deste ponto, faremos apontamentos que indicarão alguns dos caminhos que foram por nós percorridos.

Coelho (1995), baseando-se em perspectivas psicanalíticas, aponta que o amor está intimamente relacionado à fase evolutiva do desenvolvimento sexual infantil, denominada por Freud de fase oral. Em seu texto intitulado O amor e a oralidade (Coelho, 1995), o autor aponta que a questão do amor e de sua relação com a oralidade estabelece-se a partir da primeira relação de amor experimentada pela criança, a qual se ancora nos cuidados maternos e na amamentação, que contribuem para o estabelecimento de uma relação erótica entre a criança e a mãe. Essa relação caracteriza-se 
por um sentimento de indiferenciação em que a criança não distingue os contornos que delimitam e separam o seu corpo do corpo da mãe. Nesse sentido, em uma primeira definição, o autor caracteriza o amor como um sentimento de unidade entre diferentes seres que estão afetivamente ligados.

Faz-se importante mencionar também que, na fase oral, o amor encontra-se atrelado à fome, ao mesmo tempo em que a sexualidade liga-se à autoconservação do indivíduo. Em razão disso, é possível observar que o amor não se limita apenas a um processo de identificação com o outro. Esse outro posiciona-se aos olhos do amante como dotado de um valor supremo e sentido como uma necessidade vital. A partir de então, Coelho (1995) amplia a sua definição de amor como um sentimento de unidade entre diferentes seres afetivamente ligados, acrescentando a ela o fato de que, na relação amorosa, o amado assume uma importância vital para o amante.

A respeito disso, podemos apontar a contribuição dada por Nadiá Paulo Ferreira em seu livro A teoria do amor (2004). Para a autora, a dimensão do amor configura-se pela posição de sujeito, aquele que ama, e de objeto, aquele que é amado, onde o primeiro, abatido pela experiência de que alguma coisa lhe falta, ainda que desconheça 0 que é, posiciona-se como amante, enquanto o segundo, aquele que sabe que tem alguma coisa que o torna especial, ocupa o lugar de amado (Ferreira, 2004).

Tais considerações, é importante mencionar, estão em consonância com aquilo que, em $O$ seminário, livro 8: a transferência, foi tratado por Lacan (1993) a respeito da dualidade interna ao par amoroso, isto é, a respeito dessas distintas posições ocupadas por cada um na relação amorosa, que seriam a de amado, aquele que tem alguma coisa (Erómenos) e a de amante, aquele que vai em busca daquilo que lhe falta (Erastês).

Para dar conta desse objeto supostamente possuído por um e buscado por outro, Lacan (1993), ao retomar o estudo da transferência a partir do tema do amor, apresenta-nos o termo agalma. De uma forma geral, agallo significa enfeitar, ornamentar, e, nesse sentido, à primeira vista, agalma significa ornamento, enfeite. Por essa razão, no texto lacaniano, essa palavra grega oferece subsídio para que o autor a identifique como sendo um objeto precioso, um objeto que o sujeito, enamorado, localiza na pessoa amada. Tal situação, por sua vez, sustenta a crença de que, no amado, encontramos o objeto que perdemos desde sempre, o objeto que buscamos a vida inteira e que, portanto, nos é valioso (Lacan, 1993).

Sendo assim, o agalma, introduzido por Lacan (1993) no estudo da transferência, diz respeito ao objeto que nos captura, a esse algo do outro que nos apreende e nos fascina, de modo a nos deixar 
enamorados. Ainda nesse contexto, é profícuo apontar que é dessa relação de suposição que se trata o enredo dramatizado pelo personagem Alcibíades em $O$ banquete, de Platão (2010), na medida em que, ao atribuir a Sócrates a detenção de algo que lhe é precioso, de algo que lhe falta, eleva-o à posição de desejável, de amado, portanto. Em outras palavras, o que queremos dizer é que, ao acreditar que Sócrates é detentor de algo que lhe falta, o amor de Alcibíades é mobilizado por esse objeto precioso que, escondido em uma espécie de sileno, ao qual Sócrates é comparado, faz às vezes de agalma. O amor, dessa forma, estabelece-se como a esperança de captura daquilo que confere completude e totalidade ao sujeito. Essa esperança de completude e união impulsiona a idealização do amado como detentor daquilo que falta ao amante (o sujeito supõe uma riqueza interior no outro), em um fluxo que converge para a ilusão de alcance de uma felicidade suprema.

A palavra ilusão justifica-se aqui pelo fato de que a falta, constituinte do aparelho psíquico, é indissolúvel, e o amor, em meio a isso, tornase uma esfera da dimensão humana que emerge como tentativa de supressão dessa falta inerente ao aparelho psíquico.

Ainda no âmbito da psicanálise, Rios (2008) nos aponta que o amor caracteriza-se por uma ação de investimento de energia psíquica, isto é, libido, sobre um objeto, ao mesmo tempo em que é fonte de prazer e base para a construção permanente da identidade. Durante a fase do desenvolvimento psicossexual, denominada por Freud de narcisismo primário, o eu e o outro constroem-se por meio de uma relação de espelhamento, o que significa dizer que o objeto amado é visto e valorizado em razão de sua semelhança com o eu, constituindo-se, assim, uma relação amorosa do tipo narcísica (Rios, 2008).

Tal relação, entretanto, ao estabelecer-se em um ambiente no qual a criança é cuidada, alimentada e protegida de forma satisfatória, gradativamente, cede lugar a um outro tipo de relação amorosa, essa denominada anaclítica, a qual, por sua vez, caracteriza-se por não mais estabelecer-se em relação ao outro por meio da semelhança com o eu, e sim, na relação intersubjetiva, onde o outro é percebido como diferente (Rios, 2008).

Essas duas formas de amar (narcísica e anaclítica) mantêm-se, ao longo da vida, sob diferentes gradientes, tendências e inclinações, 0 que permite a afirmação de que a escolha do objeto de amor implica, inconscientemente, em uma captura narcísica. É por essa razão que o narcisismo constitui-se em uma fase normal do desenvolvimento psíquico, fundamental, vale dizer, para a constituição do eu e do lugar do outro em nossas vidas. Entretanto, é necessário que essa fase seja superada e que, assim, o eu consiga transpor o estado narcísico, tornando possível o estado da alteridade, no qual o outro, ao ser reconhecido como diferente, possa ser alguém para se amar. 
Em outras palavras, podemos afirmar que, dinamizada a fase do narcisismo, o outro assoma como um lugar precioso, uma espécie de sileno (Lacan, 1993), supostamente dotado daquilo que nos falta.

Desse modo, vale dizer que apenas um eu suficientemente bem constituído e seguro da sua capacidade de transitar pelo campo relacional, que é formado por subjetividades diferentes, é capaz de sustentar uma relação com o outro. Em outras situações, quando há dificuldades de saída do eu do estado narcísico ou retorno a ele na fase adulta, é possível detectar dificuldades no relacionamento intersubjetivo, onde, muitas vezes, pode-se observar a incapacidade do eu de, legitimamente, valorizar e interessar-se pelo outro.

Nesse sentido, Rios (2008) afirma que a possibilidade do encontro amoroso no qual a alteridade encontra-se legitimada depende da superação da fase narcísica do eu, bem como de uma cultura que mantém e reforça modelos de sustentação da intersubjetividade. Contudo, no ponto de vista da autora, as práticas e os conceitos tardo-modernos são insuficientes para a sustentação da alteridade e para a manutenção da experiência coletiva. Em razão dessas características singulares, a cultura contemporânea também pode ser denominada Cultura Narcísica, Somática ou do Espetáculo, onde o eu encontra-se em excesso, hipertrofiado, devido ao fracasso das grandes narrativas ideológicas que davam sentido ao coletivo humano e, consequentemente, à emergência da busca de sentido para a existência no miolo de si mesmo (Rios, 2008).

Com base nisso, observamos que, a partir do que Rios (2008) afirma, somos remetidos a uma discussão acerca do lugar ocupado pela alteridade nas relações amorosas contemporâneas. Em sua opinião (Rios, 2008), sem referências culturais que legitimem a experiência com o outro, o eu tem a si mesmo como objeto de amor e de sustentação da sua identidade. Sendo assim, as pessoas voltam-se para si mesmas, desinteressando-se do universo alheio em um espaço onde as relações intersubjetivas estão em ruínas. Nesse contexto, vale dizer que o encontro amoroso, aquele que não deixa obnubilada a dimensão da alteridade, tem-se mostrado um pungente fracasso.

Em outras palavras, é possível afirmar que, contundentemente narcísica, a relação contingencial sustentada pelos investimentos amorosos torna-se uma ligação displicente para com o outro. Este, por sua vez, ocupa agora o lugar de espectador de um eu que, exercendo a função de protagonista, sente prazer com a sua exibição. Nesse cenário, o amor não escapa ao princípio consumista. O que é desejado pelo eu é uma relação amorosa idealizada, onde a felicidade e o prazer, antes cultivados, agora devem ser consumidos de forma a proporcionar uma satisfação ininterrupta.

No entanto, o amor, que só se realiza na intersubjetividade e, com efeito, é marca indelével da incompletude humana - só amamos 
porque somos incompletos -, é um espaço de encontros e desencontros, sendo-Ihe impossível a garantia de eterna serenidade e calmaria. Daí, segundo a autora (Rios, 2008), a insatisfação, na sociedade contemporânea, com os custos da relação amorosa, a qual exige o exercício da tolerância, da reflexão, do diálogo e da autocrítica, em contrapartida à hipertrofia de si mesmo, entendida aqui como medida de (falsa) proteção contra as intempéries da relação amorosa.

Adentramos, assim, em um terreno que se aproxima de questões por nós levantadas no decorrer deste estudo. Ainda que de fora da perspectiva psicanalítica, o ponto de vista de Zygmunt Bauman converge para o que foi apontado por Izabel Cristina Rios. Em seu livro Amor líquido, o autor retrata a fragilidade dos vínculos humanos na contemporaneidade, marcada por um furioso processo de individualização (Bauman, 2004).

$\mathrm{Na}$ líquida sociedade moderna, o constante sentimento de insegurança faz com que os laços amorosos encontrem-se em uma situação em que o seu vigor apresenta-se comprometido. Em função disso, passam a ser atados frouxamente, de modo que, quando as condições parecerem desfavoráveis, possam ser desfeitos sem grande demanda de tempo e energia. Daí a emergência de um efeito expressivo desse modo de funcionamento dos pactos amorosos: delineados por um regime de conexões (Bauman, 2004), eles são marcados, sobremaneira, pela fugacidade dos vínculos.

Os relacionamentos humanos encontram-se, assim, em meio a uma lógica de consumo, na qual a máxima satisfação é premente e indispensável. Desse modo, ao avistar um sinal de frustração ante essa voracidade de prazer, os relacionamentos são rápida e facilmente descartados, ao mesmo tempo em que são vislumbradas novas possibilidades de investimento amoroso (Bauman, 2004).

Nesse contexto, vale dizer que a nossa compreensão do amor implica em uma relação que se estabelece como uma espécie de laço social, onde o eu é confrontado com a pregnância da existência do outro. Implica, portanto, em uma relação entre seres marcados pela alteridade, de modo a serem separados entre si pela diferença, pela particularidade e pela singularidade inerentes a cada um. Entretanto, partindo desse pressuposto, isto é, da relação amorosa como sendo o envolvimento de um eu e de um outro, identificamos, nos autores que escolhemos, que tal relação modifica-se qualitativamente, de modo que podemos observar uma série de transmutações no que diz respeito ao posicionamento do eu frente ao outro e vice-versa.

Dito isso, a fim de compilar comentários concernentes às diversas formas de acomodação do eu e do outro na relação amorosa, partimos das considerações feitas pelo filósofo Emmanuel Lévinas a respeito dessa temática. Em primeiro lugar, o amor "designa um movimento pelo qual o ser procura aquilo a que se ligou, antes 
mesmo de ter tomado a iniciativa da procura" (Lévinas, 1988, p. 233). Também o "amor continua a ser uma relação com outrem que se transforma em necessidade [que] pressupõe ainda a exterioridade total, transcendente do outro, do amado" (Lévinas, 1988, p. 234). Indo além, o erótico é simultaneamente necessidade e desejo, concupiscência e transcendência, ambiguidade do amor. Além do que, há no amor uma dualidade insuperável entre os seres - o outro sempre escapa - ou seja, a alteridade persiste.

Desse modo, para Lévinas, o amor é um sentimento que possibilita a abertura ética entre os homens. No que diz respeito ao eu, o amor é da ordem da imperatividade, o que, em outras palavras, significa dizer que o amor é uma relação com o outro que se faz necessária e obrigatória, transformando-se, assim, em um apelo, em uma força que move o agir ético (Lima, 2007).

Nesse sentido, o eu, na relação amorosa, é levado a visar o outro em sua fraqueza e em sua alteridade, ajudando-o e temendo por ele, ao mesmo tempo em que se submete a um movimento de des-interessamento de si mesmo que converge para um existir-para-o-outro. Vale dizer ainda que esse movimento, zênite da radicalidade ética de Emmanuel Lévinas, implica em uma evasão de si mesmo, cuja integralidade impede que o outro seja meio para qualquer fim. Assim, a intersubjetividade amorosa em Lévinas se dá, com efeito, em uma relação de assimetria entre o eu e o outro, onde este, não sendo artifício identitário, é exterioridade absoluta que surge em sua própria positividade, inaugurando a diferença e a separação (Lima, 2007).

Há, assim, no eu, um sentimento de responsabilidade desinteressada, espontânea e levada ao extremo, que não visa nada que não seja o seu próprio sentido de "responder por outrem", ao mesmo tempo em que prescinde da exigência de reciprocidade. $O$ amor faz-se, desse modo, como uma relação desinteressada e assimétrica do eu para com o outro. Aqui, ao primeiro, é imperativo o viver para o segundo, em um constante oferecimento de si mesmo. Em um constante pronunciar da obrigatoriedade ética circunscrita no "Eis-me aqui".

Adentramos, a partir de agora, em novas perspectivas teóricas que podem trazer outros pontos de reflexão acerca da relação amorosa, bem como do lugar nela ocupado pelas figuras do eu e do outro. Para tanto, partamos das teses de Gilles Lipovetsky no que tange às relações interpessoais nas sociedades pós-industriais.

Em seu livro $A$ era do vazio (Lipovetsky, 1989), o autor dedica um dos capítulos à discussão da sedução como um novo processo de regulamentação não apenas das relações interpessoais, mas também do consumo, das organizações, da informação, da educação e dos costumes em nossa época.

Segundo o seu ponto de vista, a sedução opera em uma lógica da sociedade da abundância, na qual é fomentada a acentuação das motivações, do bem-estar, da liberdade e do interesse individuais. 
Ademais, fundamentada por uma lógica da oferta infinita, trata-se de uma época de intensa flexibilidade que oferece inúmeras combinações e possibilidades existenciais.

$\mathrm{O}$ indivíduo, nesse contexto, encontra-se incessantemente instigado a alcançar a plenitude e a totalidade de seus desejos, em um fluxo intenso de exacerbação de seus sentidos e de sua libido, onde, à satisfação, é imperativa a ocorrência imediata e extrema. Daí decorre o que Lipovetsky (1989) pontuou como sendo um fenômeno de inflação erótica, caracterizada, primordialmente, pela redução do ser humano à categoria de objeto em uma relação estabelecida pelo uso do outro como parceiro descartável de uma ginástica sexual.

Aqui, o relacionamento amoroso segue a lógica da reificação e da ordem industrial. Estas, por sua vez, conclamam os homens a fazer uso do corpo alheio através de um modelo de produção serial, no qual é mister ir cada vez mais longe na procura pela experimentação de dispositivos corporais inéditos, frutos de novas combinações, colhidas na abundante gama de ofertas do self-service libidinal (Lipovetsky, 1989).

Ainda segundo esse autor, é preciso acumular experiências, explorar - capital libidinal pessoal e inovar em matéria de combinações, repugnando, assim, tudo o que se aproxima da imobilidade e da estabilidade, em função da soberania da experimentação e da iniciativa. Desta maneira, sob a égide do sexo, a relação amorosa, descrita por ele como característica da sociedade pós-industrial, revela uma violação daquilo que, acima, foi descrito como a ética levinasiana, no que tange à preservação e ao cuidado com o outro. Este, dessa forma, encontra-se maculado em sua alteridade, deixando de ser alvo do cuidado e da responsabilidade do eu, agora contundentemente interessado em si mesmo, para servir-lhe violentamente de fonte de prazer e satisfação.

Diante disso, como forma de ampliar nossa discussão, apresentamos, agora, a perspectiva do sociólogo Anthony Giddens, que, dentre outras questões, contribui para a elucidação da temática do amor por meio do conceito de relacionamento puro. Giddens (1993) aponta o relacionamento puro como aquele que abre espaço para uma significativa exploração da intimidade, sendo, assim, parte de uma reestruturação genérica dela. É um vínculo emocional próximo e continuado com outra pessoa, mas que, entretanto, não parte de aportes sociais que tornam a relação necessária, natural ou obrigatória. Trata-se, a bem da verdade, de uma situação em que os envolvidos apostam e investem em uma associação, em uma parceria, mantida desde que dela sejam extraídas satisfações e benefícios suficientes para garantir e justificar a sua continuidade.

Sendo assim, o relacionamento puro implica em uma abertura do eu em relação ao outro e deste em relação àquele. Exige, também, uma negociação constante entre ambas as partes, de modo que, ao 
relacionamento puro, não se encontram atreladas as noções de monogamia e heterossexualidade, por exemplo. Tais questões são relativizadas e definidas pelos parceiros envolvidos nessa associação. Ao relacionamento puro, mais especificamente pautado no que 0 autor denomina amor confluente, as categorias de 'para sempre' e 'único' não se aplicam, uma vez que o amor confluente, ativo e contingente, afasta-se da procura da 'pessoa especial', à medida que busca consolidar um 'relacionamento especial' (Giddens, 1993).

É possível, a partir do que foi exposto até então, observarmos que o amor confluente presume uma relação simétrica entre o eu e o outro, de modo que, no âmbito da intimidade, a vulnerabilidade de um em relação ao outro é valorizada. Além disso, presume-se uma paridade na doação e no recebimento emocionais, na medida em que ambos devem manifestar seu compromisso, suas preocupações e suas necessidades no que diz respeito à relação assumida. $O$ eu encontrase vulnerável ao outro e vice-versa, de modo que as peculiaridades de cada um não sejam apenas conhecidas, mas, também, consideradas.

Assim sendo, no âmbito do relacionamento puro, no que diz respeito à continuidade da união, percebemos que ela pode ser findada por qualquer dos parceiros, em qualquer momento particular. A sua durabilidade, nesse caso, depende não de apoios externos, e sim do compromisso com a relação e, consequentemente, com o outro. Compromisso esse, por sua vez, oriundo da doação de uma pessoa à outra, na medida em que ambas desejam formular uma história compartilhada (Giddens, 1993).

Dessa forma, refutando-se a ideia de durabilidade como "condição natural" e, portanto, como certa e inquestionável, recorre-se à confiança, cuja base encontra-se na intimidade da relação. Trata-se, assim, de um sentimento de fé no outro e na capacidade do laço mútuo em resistir a traumas futuros.

A confiança no outro implica, ao mesmo tempo, a possibilidade de ruptura ante os grilhões que tornam o sujeito prisioneiro das exigências de um eu possessivo. Salvaguardam-se, assim, a liberdade e a singularidade do outro, ideia que, comparativamente às teses aqui apresentadas, aproxima-se da relação amorosa descrita por Lévinas e, consequentemente, afasta-se das formas de relação amorosa descritas por Lipovetsky, em que a posse do outro engendra um movimento de afastamento do Eros.

Dessa forma, ao retomarmos o que, até então, foi trabalhado, percebemos que, no presente texto, iniciamos a nossa discussão por meio do enfoque psicanalítico. Sob essa perspectiva, o amor se configura como suplemento de um encontro sempre faltoso entre 0 sujeito e a sexualidade. Nesse sentido, alimenta a ilusão de completude perdida e, dessa forma, proporciona um certo 
apaziguamento do desejo humano, tornando-o, assim, tolerável em seu mal-estar (Ferreira, 2004).

No que diz respeito a esse ponto, consideramos oportuno acrescentar que a dimensão do amor como esfera desejável e necessária à condição humana encontra convergência na ideia freudiana de que a relação amorosa é uma das formas de leniência para o desamparo e o sofrimento humanos (Freud, 1996). Em outras palavras, queremos dizer que Freud (1996) atribui, ao amor, a capacidade não apenas de evitar o desprazer, inextrincável à experiência humana, mas, também, dada a sua potência de criação, o atributo de possibilitar o encontro com a felicidade.

Desse modo, o amor, ancorado na satisfação pulsional que ele proporciona, consiste em uma das estratégias humanas mais potencialmente acalentadoras ainda que, paradoxalmente, também concentre em si mesma um núcleo de devastação, uma vez "que nunca nos achamos tão indefesos contra o sofrimento como quando amamos, nunca tão desamparadamente infelizes como quando perdemos o nosso objeto amado ou o seu amor." (Freud, 1996, p. 90). Isso, contudo, pondera Freud (1996), não elimina daquilo a que ele denominou "técnica de viver fundamentada no valor do amor" o seu caráter de possibilitar uma experiência de felicidade. "Em nenhum outro caso, Eros revela tão claramente o âmago do seu ser, o seu intuito de, de mais de um, fazer um único" (Freud, 1996, p. 113).

Entretanto, no avançar de nossa investigação, pudemos verificar que, em meio a uma sociedade pautada pela lógica do consumo e sob a hegemonia de um eu, predominantemente, narcísico e soberano, há uma deterioração da relação amorosa no que tange ao dispêndio de energia necessário ao seu cultivo. Nesse contexto, conforme apontamos linhas acima, a fugacidade das relações amorosas, isto é, dos pactos estabelecidos, apresenta-se como um sinal de fragilidade dos vínculos existentes entre o eu e o outro, ao passo que este índice da dimensão da alteridade - assoma preterido.

Desta feita, com o intuito de compendiar os autores que alimentaram a nossa discussão, observamos que o imperativo negativo "não matarás", que se converte em "eu te amarei", segundo a ética levinasiana (Lima, 2007), encontra-se em decadência, uma vez que, de acordo com o que foi postulado por Gilles Lipovetsky e por Zygmunt Bauman, esse "não matarás" segue a lógica da soberania narcísica e se estabelece como um "eu te usarei". Ainda nessa seara, algo que, em meio a essa discussão contemporânea da relação amorosa, nos pareceu inclinado a salvaguardar o lugar do outro e, assim, reduzir o seu jugo frente a um eu voraz e egoísta, encontra-se na ótica do relacionamento puro. Sob essa perspectiva, observamos que o "não matarás" pode aparecer, desde que previamente 
consentido, como um "nós nos amaremos... mútua e conscienciosamente".

Diante disso, consideramos importante mencionar que as leituras aqui apresentadas serviram-nos de suporte para a compreensão de que a variabilidade dos enfoques teóricos que se debruçam sobre a tônica amorosa nos conduz à assertiva de que o amor é um assunto polissêmico de interesse universal. Contudo, vale dizer também que a temática do amor mantém-se como uma fonte inesgotável de investigação, de modo que sua compreensão absoluta persiste inapreensível à especulação e à teorização, advindas dos mais diversificados campos do saber. No entanto, estes nos auxiliam a perceber que, diante de tantas formas de encarar a vinculação amorosa e, consequentemente, as suas relações com a alteridade, amantes e amados se posicionam um frente ao outro de acordo com fatores psicológicos, sociais e culturais que assinalam, ao mesmo tempo, a singularidade de cada encontro, de cada eu e de cada outro. Assim sendo, a partir dos autores apresentados, ainda que tenham sido pauta de nossas discussões as relações de dependência constitutiva (Coelho, 1995), de doação incondicional (Lévinas, 1988), de conexões temporárias (Bauman, 2004), de perjuro e submissão (Lipovetsky, 1989) e, por fim, de parceria consentida (Giddens, 1993), o amor, permeado por determinações subjetivas e por influências externas, é um encontro singular que, em meio à variabilidade de suas narrativas e às leituras que intentam compreendê-lo, mantém-se como uma experiência vital para a condição humana. É que o amor apresenta-se, para nós, como um artefato marcado pelo saber-fazer com a incompletude. E aqui, vale dizer, encontram-se, necessariamente, implicadas, as dimensões da alteridade e também da criação.

Nesse contexto, em tempos em que vínculos duradouros não parecem mais surtir efeitos na civilização e uniões transitórias e múltiplas parecem nos indicar a fragilidade de um pacto simbólico (Soller, 2005), para além do imperativo ético, apregoado por Lévinas, e da falta constituinte do sujeito, defendida pela psicanálise, apontamos aqui a importância de uma dimensão estética do amor.

Neste sentido, considerando-se a singularidade de cada encontro, defendemos a possibilidade de, por meio da beleza e da dialética amorosa - que sempre implicam expansão -, engendrar-se o novo. Para nós, desacorrentar-se dos grilhões de um amor opressor, que, portanto, prescinde de Eros e subjuga o outro, requer a dinâmica do amar e ser amado. Não no sentido da reciprocidade, como somos levados a acreditar, mas sim, no sentido do livre curso dos sujeitos entre as posições de Erastes e Erómenos (Maurano, 2006).

Dessa forma, com o intuito de apontarmos uma saída para a problemática que apresentamos, qual seja, aquela que diz respeito à debilidade dos laços amorosos na contemporaneidade (Bauman, 
2004) e ao enfraquecimento do estatuto do outro na relação amorosa (Rios, 2008), utilizaremos aqui o que pode ser considerado como uma profícua e atemporal referência para questões acerca do amor. Contudo, antes de chegarmos a ela, vale esclarecer, em primeiro lugar, que a fragilidade identificada por Bauman (2004) não diz respeito, primordialmente, à durabilidade das relações amorosas. Conforme apontamos linhas acima, a efemeridade das relações é um efeito secundário e vale como índice revelador das dificuldades de investimento e cultivo dos pactos amorosos. Nessa direção, vale dizer que estes se apresentam barateados e simplificados por um sistema frágil de elementares e múltiplas conexões (Bauman, 2004). Ademais, é nesse contexto que identificamos que, na contemporaneidade, em razão da frugalidade dos investimentos e da economia narcísica que os sustenta, o lugar reservado à alteridade encontra-se comprometido, à medida que o outro emerge, significativamente, perjurado.

Assim sendo, independentemente do tempo de duração de uma relação amorosa, o que se encontra premente é o reconhecimento de que o amor implica não só uma relação com o outro, como, igualmente, um exercício dispendioso e laborioso de invenção. Nesse contexto, em O Banquete, de Platão (2010) - a referência que dissemos ser profícua e atemporal -, Sócrates afirma que, de acordo com Diotima, uma mulher de Mantinea que Ihe instruiu a respeito do amor, há uma relação entre este e a palavra poiesis. Tal relação se estabelece na medida em que poiesis, em grego, significa, originalmente, a ação de fazer, de produzir, em outras palavras, a ação de passagem do "que quer que seja do não ser ao ser" (Maurano, 2006). Daí decorre, por sua vez, uma relação com a criação, de modo que, condição para a vitalidade humana, o amor, como estruturante, deve ser, também, criador.

Antes de prosseguirmos em nossas considerações, vale lembrar que o lugar reservado à alteridade nas relações amorosas na contemporaneidade foi 0 expediente disparador de nossa investigação. Para trilhar esse caminho, convocamos, na qualidade de suporte teórico, os conceitos conjecturados pela psicanálise, pela filosofia e pela sociologia. Com isso, compreendemos que, seja por uma via psíquica, ética ou social, a alteridade impõe-se ao estabelecimento dos laços amorosos e, como reduto significativo da diferença, engendra, ao mesmo tempo, um movimento particular de invenção.

Diante disso, encaminhamo-nos para uma compreensão de que, em termos de qualidade, legitimidade e durabilidade, o amor, a despeito dos discursos normativos, falados por milhares de sujeitos, mas sustentados por ninguém, não é da ordem do êxito ou do fracasso, da vitória ou da derrota, mas sim, conforme aponta Barthes (2003), da ordem (dionisíaca) do lançamento de dados e, ao mesmo tempo, 
da afirmação. Nesse contexto, Roland Barthes, um importante articulista do amor, oferece-nos aqui uma leitura que nos habilita a transcender o expediente disparador de nossas considerações - o lugar da alteridade nas relações amorosas na contemporaneidade para alcançar uma dimensão outra, aquela que conjuga o amor, a alteridade e a criação.

Assim, caucionados pelo suporte que Roland Barthes nos oferece, observamos que o amor, alinhado à necessidade de supor a existência do outro em toda a sua legitimidade, depara-se com a sempre patente possibilidade de assombramento e desencontro. Por essa razão, requer um trabalho insistente, no qual um "demônio nega o tempo, o amadurecimento, a dialética e diz a cada instante: isso não pode durar! Contudo, isso dura, se não para sempre, ao menos por muito tempo" (Barthes, 2003, p. 229).

Ocorre que a situação amorosa, em contraposição à razoabilidade, em que tudo se ajeita e nada dura, é da ordem do que nada se ajeita, contudo, dura (Barthes, 2003), pois, na medida em que, contra tudo e contra todos, é afirmada como valor, encontra-se arraigada a uma dimensão de errância sempre reinventada.

É daí, portanto, que o amor extrai a conotação fundamentada em uma dialética de sínteses intermitentes, as quais exigem, por sua vez, um trabalho permanente de criação, tendo em vista o seu caráter contínuo, lança ao amor uma dimensão de temporalidade que, para além do tempo cronológico, imprime-lhe uma narrativa. Esta, subjetivada, arvora-se em uma história de amor, a qual, sustentada pelo desejo e, portanto, em constante tensão com a opinião geral que deprecia a sua força, revela a exuberância de sua originalidade.

Vale dizer que aqui vemos sobrepujada uma noção de durabilidade que se restringe à contagem do tempo. Na medida em que o amor é afirmado como valor que, ao convocar uma aliança com o outro, torna-se capaz de fundar uma nova poiesis, o tempo é escalonado em uma história, isto é, em uma narrativa de amor que testemunha, por sua vez, não a fragilidade ou a fugacidade, mas a força dos investimentos, a deferência à alteridade e a importância qualitativa dos laços.

Em outras palavras, o que queremos apontar é que o amor, afirmado como valor, encarado como trabalho de criação e, por fim, sustentado pelo desejo - que supõe um objeto a ser investido -, encerra uma dimensão radical de originalidade. Esta, vale dizer, salvaguarda o amante da necessidade de, com fins de adaptação, sacrificar sua história de amor e, outrossim, o seu objeto de desejo, como tributos a serem pagos aos ditames de um mundo (Barthes, 2003) prescrito, com efeito, segundo uma lógica hedonista de consumação (Lipovetsky, 1989). 
Nessa direção, retomamos o lugar do outro na relação amorosa e, tendo como contexto o que apontamos nos últimos parágrafos, sentimo-nos aptos a afirmar que, nessa dinâmica amorosa em que o amor é uma errância, constantemente reinventada, ao outro cabe o papel de ser, para o sujeito enamorado, aquele que designa a especialidade de seu desejo (Barthes, 2003). Dito de outra forma, queremos assinalar que, dada a impossibilidade de relação amorosa que prescinda da dimensão da alteridade, Roland Barthes (2003) oferece-nos uma solução, ao passo que confere, ao outro, o estatuto de horizonte referencial para aquilo que ultrapassa, ventila e dinamiza a própria dimensão do amor, ou seja, o desejo, esta engrenagem que, marcada pela falta, evoca o matiz da criação.

Contudo, conforme apontado por Barthes (2003), vale lembrar que "à precisão do alvo corresponde um tremor do nome" (p. 12), no sentido de que o próprio do desejo, isto é, a sua especialidade, remete, inevitavelmente, ao impróprio do enunciado, em outras palavras, à impossibilidade de nomeação, de modo que o outro, o amado, na medida em que desvela o desejo do amante, só pode ocupar uma dimensão do que é inapreensível, intransponível, ou seja, enigmático. Como nos diz Roland Barthes:

É atopos o outro que eu amo e que me fascina. Não posso classificá-lo, pois que ele é precisamente o Único, a Imagem singular que veio miraculosamente responder à especialidade de meu desejo. É a figura de minha verdade; não pode ser encaixado em nenhum estereótipo (que é a verdade dos outros) (Barthes, 2003, p. 31).

Assim, não podendo conhecer o outro, que desperta o desejo, não se pode conhecer a si mesmo, de modo que o enigma desejante, do eu e do outro, mantém-se como engrenagem essencial à dinâmica da relação amorosa. A ela, contudo, destina-se o lugar da originalidade, de uma singularidade que é preciso conquistar, como modo mesmo de apaziguamento de uma relação abalada, mortificada e coagida pelo ressentimento que vem dos regimes narcisistas, dos estereótipos consumistas e dos discursos normativos: "quando a relação é original, o estereótipo é abalado, ultrapassado, evacuado, e o ciúme, por exemplo, já não tem lugar nessa relação sem lugar, sem topos, sem 'topo' - sem discurso" (Barthes, 2003, p. 33).

Desta feita, encaminhando-nos para o fechamento de nosso texto, é preciso apontar que o amor, que tem, certamente, um pacto com a linguagem, não é passível de ser alojado na escrita, de modo que se faz imperativo assinalar a derrocada da ilusão de sua expressividade (Barthes, 2003). Nesse sentido, vale destacar que o amor é vivido, e, conforme apontado por Freud (1996), pode ser adotado como uma das modalidades das "técnicas de viver", capazes de apaziguar as 
experiências de mal-estar, inerentes à condição humana. Daí decorre, segundo o nosso ponto de vista, que, não obstante serem perjurados em meio a economias e discursos que dificultam a sua afirmação, 0 amor e os pactos amorosos continuam persistindo em sua capacidade de fascinar e mobilizar energias e variadas discussões.

Ocorre que, conforme aponta o poeta, sempre um perito nos assuntos amorosos, "o amor é difícil" (Rilke, 2013, p. 54). Trata-se de uma das tarefas mais labirínticas da experiência humana. Nesse sentido, talvez seja exatamente por essa razão que é, ao mesmo tempo, um terreno tão cheio de convenções e de narrativas que, inclinadas a considerar a vida amorosa um contínuo prazer, esforçam-se por torná-la fácil, barata e segura (Rilke, 2013).

Contudo, conforme apontado por Rilke (2013), aqueles que examinarem a questão com maior seriedade podem alcançar a clarividente perspectiva de que o amor e a potência de suas cargas não se limitam a uma brincadeira leviana "que serve aos homens para se subtraírem ao problema mais grave de sua existência" (Rilke, 2013, p. 57). É, antes, uma espécie de tirocínio que confere, à alteridade e à relação amorosa, o valor de lugar onde podemos, com efeito, aprender sobre nós mesmos. "O amor é uma ocasião sublime para o indivíduo amadurecer, tornar-se algo em si mesmo, tornar-se um mundo para si, por causa de um outro ser; é uma grande e ilimitada exigência que se lhe faz, uma escolha e um chamado para longe" (Rilke, 2013, p. 55).

É, portanto, uma oportunidade para trabalhar em si mesmo (Rilke, 2013), de modo que tal assertiva, na contramão de uma economia hedonista, onde o eu encontra-se em excesso e hipertrofiado (Rios, 2008), oferece-nos, oportunamente, um suporte antagonista a uma lógica que deixa ultrajada a dimensão da alteridade.

Entretanto, antes de, efetivamente, concluirmos as nossas considerações, julgamos válido apontar uma derradeira ponderação. Ocorre que, assim como para os assombros da morte - outro grande pilar das inquietações humanas -, para as dificuldades do amor, "não foi encontrada uma luz, uma solução, um aceno ou um caminho" (Rilke, 2013, p. 57).

De acordo com Rilke (2013), para ambas essas esferas da vida, não há nenhuma regra comum, fundamentada em convenções ou em acordos universais. Nesse sentido, com o fito de endossar essa questão, observamos que Freud alinha-se favoravelmente ao poeta quando anuncia que, no que tange à gestão do mal-estar, índice da pregnância da incompletude $e$, por vezes, da avassaladora precariedade da condição humana, não "existe uma regra de ouro que se aplique a todos: todo homem tem de descobrir por si mesmo de que modo específico ele pode ser salvo" (Freud, 1996, p. 91).

Desse modo, diante do exposto, observamos por fim que, na esfera específica dos nós amorosos, "nossas tentativas de viver tais relações 
ainda não têm um modelo diante de si" (Rilke, 2013, p. 57). Confrontados com a dimensão irredutível da incompletude e da alteridade, em matéria de amor, somos convocados a inventar. E nisso reside toda a beleza da criação.

\section{Referências}

Bauman, Z. (2004). Amor líquido: sobre a fragilidade dos laços humanos. (Medeiros, C. A., Trad.) Rio de Janeiro: Zahar. (Obra original publicada em 2003).

Barthes, R. (2003). Fragmentos de um discurso amoroso. (Aguiar, M. V. de, Trad.) São Paulo: Martins Fontes. (Obra original publicada em 1977).

Coelho, J. R. (1995). O amor e a oralidade. Princípios, II (3) 86-91.

Ferreira, N. (2004). A teoria do amor na Psicanálise. Rio de Janeiro: Jorge Zahar Editor.

Freud. S. (1996). O mal-estar na civilização. In: Freud, S. Edição standard brasileira das obras psicológicas completas de Sigmund Freud, v. XXI. (pp. 73-150). Rio de Janeiro: Imago. (Obra original publicada em 1930).

Giddens, A. (1993). A transformação da intimidade: sexualidade, amor e erotismo nas sociedades modernas. (Lopes, M., Trad.) São Paulo: Editora UNESP.

Lacan, J. (1993). O seminário, livro 8: a transferência. (Estrada, D. D., Trad.) Rio de Janeiro: Jorge Zahar. (Seminário ministrado em 1960/1961).

Lévinas, E. (1988). Totalidade e Infinito. (Ribeiro, J. P., Trad.) Lisboa: Edições 70.

Lima, V. B. M. (2007). O conceito de amor em Emmanuel Lévinas. Recuperado em 20/05/2015, http://www.sapientia.pucsp.br//tde_busca/arquivo.php?codArq uivo $=5660$.

Lipovetsky, G. (1989). A era do vazio: ensaios sobre o individualismo contemporâneo. Baurueri: Editora Manole.

Maurano, D. (2006). A transferência: uma viagem rumo ao continente negro. Rio de Janeiro: Zahar.

Platão. (2010). Apologia de Sócrates, O Banquete e Fedro. Coleção Folha Livros que Mudaram o Mundo, v.5. São Paulo: Folha de São Paulo.

Rilke, R. M. (2013). Cartas a um jovem poeta e $A$ canção de amor e de morte do porta-estandarte Cristóvão Rilke. São Paulo: Globo.

Rios, I. C. (2008). O amor nos tempos de Narciso. Comunicação, saúde, educação, 2(25), 421-6. 
Soller, C. (2005). O que Lacan dizia das mulheres. Rio de Janeiro: Zahar.

\section{Endereço para correspondência}

\section{Rebeca Gomes}

Universidade Federal do Ceará - UFC

Centro de Humanidades, Departamento de Psicologia

Avenida da Universidade, 2762, Benfica, CEP 60020180, Fortaleza - CE, Brasil

Endereço eletrônico: rebeca_carolinne@hotmail.com

\section{José Célio Freire}

Universidade Federal do Ceará - UFC

Centro de Humanidades, Departamento de Psicologia

Avenida da Universidade, 2762, Benfica, CEP 60020180, Fortaleza - CE, Brasil

Endereço eletrônico: celiofreire@hotmail.com

Recebido em: 30/06/2015

Reformulado em: 31/05/2017

Aprovado em: 04/06/2017

\section{Notas}

* Graduada em Psicologia pela Universidade Federal do Ceará (UFC). Mestranda do Programa de Pós-graduação em Psicologia da UFC. Psicanalista. Membro em Formação Permanente da Escola de Psicanálise Corpo Freudiano - Fortaleza.

** Professor Titular do Departamento de Psicologia e do Programa de Pósgraduação em Psicologia da Universidade Federal do Ceará. Doutor em Psicologia pela Universidade de São Paulo com pós-doutorado em Psicologia Social pela Universidad Complutense de Madrid. 